\title{
Complications of vascular access in children with chronic end-stage renal disease
}

\author{
Cristina Filip ${ }^{1,5}$, Georgiana Nicolae ${ }^{1}$, Veronica Marcu', Mihaela Bizubac ${ }^{4}$, \\ Catalin Cirstoveanu ${ }^{4,5}$, Mihaela Balgradean ${ }^{2,5}$, Alin Nicolescu ${ }^{1}$ \\ ${ }^{1}$ Department of Pediatric Cardiology, "M.S. Curie” Emergency Clinical Hospital for Children, \\ Bucharest, Romania \\ 2Department of Pediatric Nephrology, "M.S. Curie" Emergency Clinical Hospital for Children, \\ Bucharest, Romania \\ ${ }^{3}$ Department of Radiology, "M.S. Curie" Emergency Clinical Hospital for Children, \\ Bucharest, Romania \\ ${ }^{4}$ Neonatal Intensive Care Unit, "M.S. Curie" Emergency Clinical Hospital for Children, Bucharest, Romania \\ 5"Carol Davila" University of Medicine and Pharmacy, Bucharest, Romania
}

\begin{abstract}
Introduction. Obtaining vascular access that allows long-term hemodialysis of children with stage 5D chronic kidney disease is a priority in the management of these patients. Complications of central venous catheters and arteriovenous fistula are directly correlated with the morbidity and quality of life of these children.

The objective of the study was to assess complications of vascular access in children on long-term hemodialysis by arteriovenous fistula or central venous line.

Methods. We followed 40 patients in the hemodialysis program for a period of 18 months; in 22, vascular access was by arteriovenous fistula, and 18 were dialyzed on a central venous line.

Results. All 22 patients were accepted for AVF at a vein diameter of at least $3 \mathrm{~mm}$, and this probably contributed to the high rate of primary maturation $(86 \%)$. In the majority of these patients $(64 \%)$ was brachiocephalic fistula versus radiocephalic (18\%), in most cases the decision being supported by small diameters of radial artery and distal cephalic vein. Three of the arteriovenous fistulas performed had a primary failure, and one a secondary failure; 2 of the patients with arteriovenous fistula failure had to be subsequently dialyzed by central venous line and one by peritoneal dialysis, while the fourth benefited from a new arteriovenous fistula. Six patients developed fistula aneurysms, one of them evolving into a pseudoaneurysm with spontaneous rupture and hemorrhagic shock and requiring emergency ligation. Two patients developed significant vein stenosis in the proximity of the anastomosis. All 6 patients with aneurysmal fistula had hypertension, and 3 of them had thrombotic venous stenoses/occlusion in the main deep veins upstream of the fistula in the context of prolonged use of central venous lines in the jugular veins and subclavian veins. The average age of the children was 13.35 years (range 9-18 years) and the average weight was $38.6 \mathrm{~kg}$ (range 23-58 kg). Of the patients on dialysis on central venous lines, $76 \%$ (16 patients) had at least one episode of sepsis that required hospitalization, and all patients who were dialyzed on the catheter (from the beginning or after fistula failure) experienced at least one episode of vein thrombosis that required catheter change. In $8(38 \%)$ of the 21 patients using central venous lines, thrombotic occlusion/stenosis of at least one persistent deep vein was observed at 3 months after the removal of the central venous line from the venous axis.

Conclusions. Complications of venous access in children with hemodialysis are very common and have a major impact on the morbidity and quality of life of these patients. In this context, a multidisciplinary team (pediatric nephrologist, specialist in vascular imaging, and vascular surgeon) is needed to follow these patients in order to prevent and treat these complications.
\end{abstract}

Keywords: arteriovenous fistula, vascular access, hemodialysis, chronic kidney disease, children

\section{Abbreviations}

$\mathrm{AVF}=$ arteriovenous fistula;

$\mathrm{AVG}=$ arteriovenous grafts;

$\mathrm{CVL}=$ central venous line,

$\mathrm{ESRD}=$ end-stage renal disease;
ESPN Dialysis WG = European Society for Pediatric Nephrology Dialysis Working Group; $\mathrm{HD}=$ hemodialysis;

IPHN = International Pediatric Hemodialysis Network;

K-DOQI = Kidney Disease Outcomes Quality Initiative 


\section{INTRODUCTION}

Proper vascular access is a key factor in the treatment of children on hemodialysis (HD) and is represented by three variants: tunneled central venous catheters (CVLs), arteriovenous fistulas (AVFs), and arteriovenous grafts (AVG) that use biological or prosthetic material [1].

Recently, the European Society for Pediatric Nephrology Dialysis Working Group (ESPN Dialysis WG) developed a guideline with recommendations on choosing the type of venous access, preoperative evaluation, monitoring, and prevention of complications of different types of venous access in children with chronic end-stage renal disease (ESRD) [1].

Although in adult patients with HD the "fistula first" principle is recognized for vascular access, in children it is not yet widely applied. In a group of 552 children prospectively followed in the International Pediatric Hemodialysis Network (IPHN) Registry with 870 venous accesses, only $26 \%$ were AVFs, while $72 \%$ were CVLs [2]. CVLs allow for relatively easy mounting, immediate use, and needle-free dialysis, but have multiple disadvantages, including infections, thrombosis, and stenosis, that can lead to central vein obstruction and reduced chances of developing AVF in the future $[3,4]$. Although AVFs have a significant primary failure rate $(25 \%$ in children [4] and up to $40 \%$ reported in adult patients [5]) and long maturation times, and require highly experienced vascular surgeons, they have the advantages of a lower rate of infections, fewer hospitalizations, and greater longevity than CVLs.

Although microvascular surgery techniques allow the creation of an AVF at body weights $<10 \mathrm{~kg}$, the Kidney Disease Outcomes Quality Initiative (K-DOQI) guidelines still recommend that it be performed at a weight $>20 \mathrm{~kg}$ in patients under 19 years of age who are not expected to receive a kidney transplant in the following year; vascular access should be created approximately 3 months before the estimated time of AVF use [1]. Many variables are cited as causes of primary AVF failure, but initial vein diameter appears to be the most important predictor of fistula maturation [6]. A study that included $83 \%$ radiocephalic AVFs showed that even low body weight was an independent predictor of primary failure [7].

One of the main complications of AVF is the formation of aneurysms in the fistula vessels. Given that the purpose of creating a fistula is to achieve vascularization of increased caliber, defining an aneurysm in this situation is difficult. Pseudoaneu- rysm generally occurs at the puncture site or anastomosis and is a hematoma that communicates with the vascular lumen of the fistula. Over time, it may develop a fibrous sac without endothelium or vascular wall structures. True aneurysms are harder to define; the proximal fistula artery dilates and remodels in response to increased blood flow, and the vein of the fistula increases its diameter at least three times until maturation. Most AVFs have a sinuous trajectory and are asymmetrically dilated (Figure 1). Pasklinsky and colleagues described as aneurysms the dilation of the vessel to at least three times the diameter of the native vessel, with a minimum size of at least $2 \mathrm{~cm}[8,9]$. Rajput et al. defines an aneurysm as a focal dilation of the AVF vein up to a diameter at least two times larger than the adjacent normal venous segment of the AVF [10].

While pseudoaneurysms are primarily a result of surgery, infection, or puncture followed by prolonged bleeding, the cause of aneurysms is less clear. Repetitive puncture leads to multiple fibrous scars in the vessel wall, which can expand over time to form localized aneurysms. With the appearance of these aneurysmal areas, the increased blood flow increases parietal stress, favoring eccentric remodeling and additional increase in vessel diameter [11]. Aneurysms may occur upstream or downstream of stenoses present in the AVF.

The natural evolution of aneurysms is usually benign, with a low risks of rupture or to affect functioning of the fistula. The risk of rupture should be considered only in case of a rapid increase in size, local pain, infection or change in the overlying skin. These changes can cause a subcutaneous rupture or a free rupture of the skin [12]. If an aneurysm has ruptured or is at imminent risk of rupture (with ulceration or local infection of the skin), emergency ligation is required. Depending on the anatomy of the fistula, AVF can be saved, but in these situations priority is given to the prevention and control of life-threatening hemorrhages. In less urgent situations, the therapeutic options are surgical or interventional. Endovascular techniques have been used in the treatment of AVF aneurysms and have relied on the use of a coated stent or stent-graft to rule out the aneurysm, but this technique compromises subsequent puncture in the stented area [13-15].

\section{AIM}

The objective of the study was to evaluate complications of vascular access in children on longterm hemodialysis by arteriovenous fistula or by central venous line. 


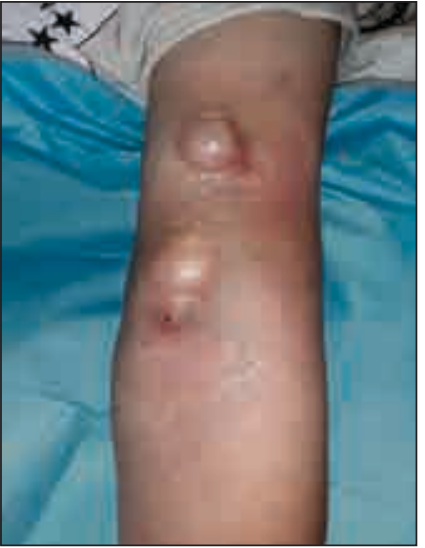

a. Clinical aspect

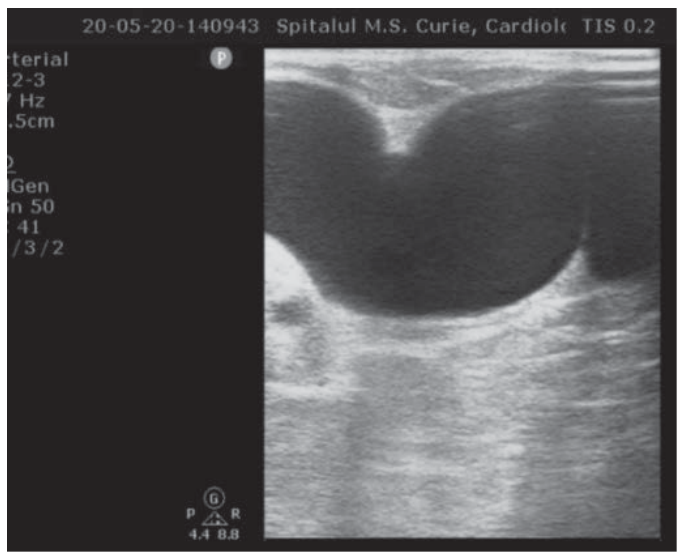

b. Ultrasound aspect (longitudinal image)

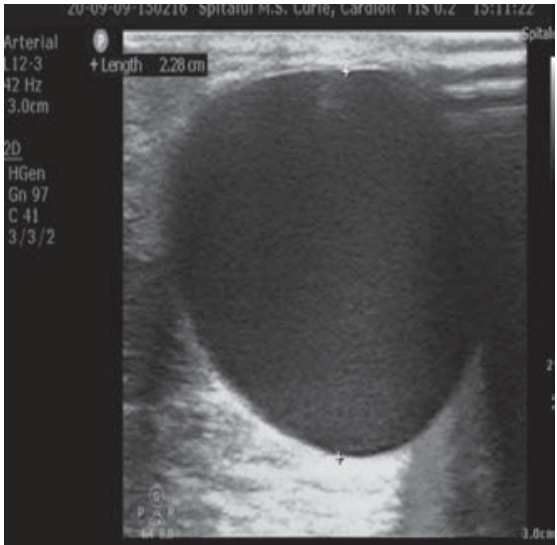

c. Ultrasound aspect (transversal image)

FIGURE 1. Aneurysms located at the puncture sites in a 14-year-old child with a functional AVF for 12 months

\section{METHODS}

We performed an 18-month follow-up of complications associated with two types of vascular access, AVF and CVL, in 42 children with hemodialysis undergoing treatment in the Hemodialysis Department of the Children's Clinical Hospital "M.S. Curie". There were 22 patients dialyzed by use of an AVF fistula (group 1), and 20 by use of a CVL (group 2). AVFs were mostly brachiocephalic (Figure 2). Patients were followed clinically and by vascular ultrasound at 6 -month intervals. The characteristics of the study population are summarized in Table 1. The processing of clinical and paraclinical data was performed by creating a Microsoft 365 Excel 2010 database. Central tendency measurements (mean average), variability (standard deviation - SD) and percentages were used for statistical analysis.

TABLE 1. Patient demographic data

\begin{tabular}{|c|c|c|}
\hline Patient features & $\begin{array}{l}\text { Patients group } 1 \\
(\mathrm{n}=\mathbf{2 2}) \text { AVFs }\end{array}$ & $\begin{array}{l}\text { Patients group } \\
2(n=20) \text { CVLs }\end{array}$ \\
\hline Median age - years (SD) & $\begin{array}{c}13.35 \\
(14.2 \pm 2.8) \\
\end{array}$ & $\begin{array}{c}12.7 \\
(13.75 \pm 2.86) \\
\end{array}$ \\
\hline Median weight - kg & $38.6(23-58)$ & $40.05(13-87)$ \\
\hline Sex (male) & $10(45.4 \%)$ & $7(35 \%)$ \\
\hline \multicolumn{3}{|l|}{ Underlying renal pathology } \\
\hline $\begin{array}{l}\text { Renal malformations/ } \\
\text { urinary tract } \\
\text { malformations }\end{array}$ & $6(27.2 \%)$ & $3(15 \%)$ \\
\hline $\begin{array}{l}\text { Neurogenic bladder + } \\
\text { recurrent urinary tract } \\
\text { infections }\end{array}$ & $5(22.7 \%)$ & $6(30 \%)$ \\
\hline Glomerulopathy & $10(45.4 \%)$ & $8(40 \%)$ \\
\hline Renal cystic disease & $1(4.5 \%)$ & $1(5 \%)$ \\
\hline $\begin{array}{l}\text { Renal vein thrombosis } \\
\text { (thrombophilia) }\end{array}$ & & $2(10 \%)$ \\
\hline
\end{tabular}

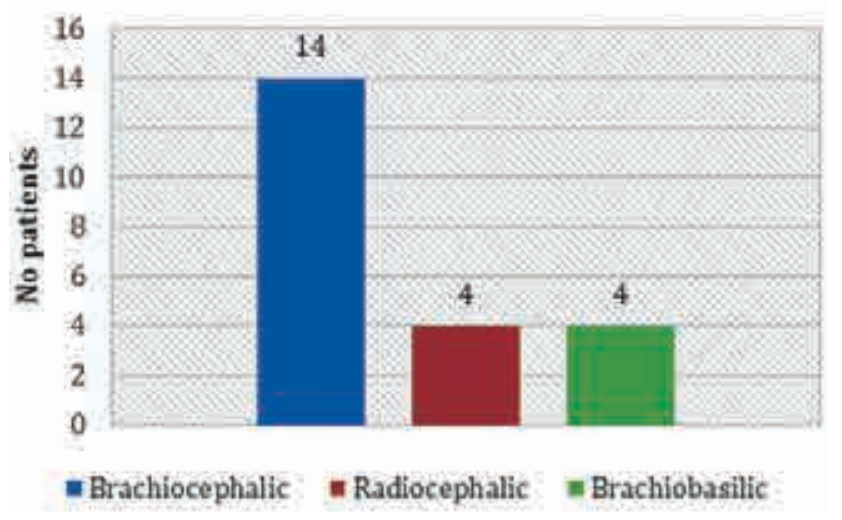

FIGURE 2. AVF types in group 1 of hemodialysis patients

\section{RESULTS}

At 18 months after inclusion in the study, 16 of 22 AVFs in the group 1 patients were still functional. The primary maturation rate was $86 \%(19 / 22$ AVF). Three AVFs had a primary failure (i.e., they could not be used within the first 3 months after their formation [6]) and one had a secondary failure. Two of the 3 primary failures correlated with a small diameter of the cephalic vein $(3 \mathrm{~mm})$ at the time of intervention, and the third case was due to a fistular thrombosis in a patient with hereditary high-risk thrombophilia (antithrombin III deficit).

Two of the fistulas were ligated by necessity, one on an emergency basis for rupture of a superficialized basilic vein pseudoaneurysm and the second for the imminent rupture of a cephalic vein aneurysm. Of the 6 patients who could no longer benefit from the fistula performed at enrollment in the study, 2 received another AVF, 3 continued the dialysis on CVLs, and one began peritoneal dialysis. 
The AVF complications that occurred during the study (Figure 3 ) were the development of aneurysms (6 cases), pseudoaneurysm ( 1 case), stenosis in the proximity of the anastomosis (2 cases), and local infection ( 1 case). All 6 cases of AVF aneurysm were associated with uncontrolled or partially controlled hypertension under treatment. Three were associated with occlusive thrombosis of the deep venous axis upstream of the fistula (uni- or bilateral brachiocephalic trunk occlusion, superior vena cava occlusion), all having clinical manifestations consisting of significant edema of the cephalic extremity and the presence of marked collateral circulation (example in Figure 4).

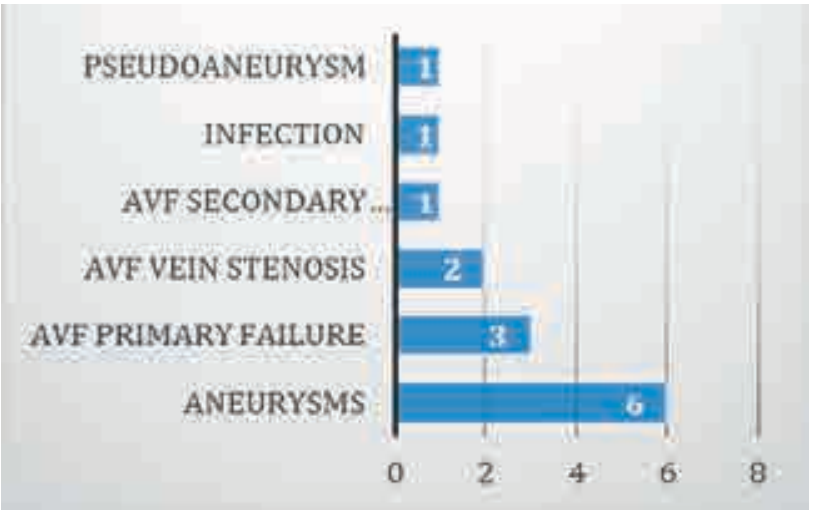

FIGURE 3. Complications of AVF (number of patients).

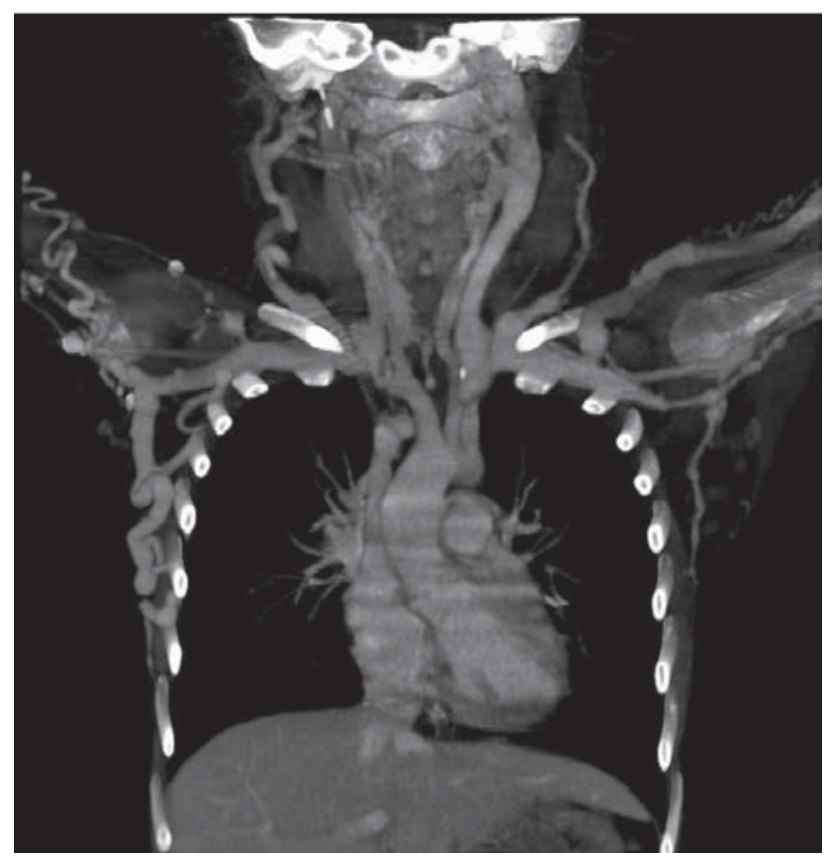

FIGURE 4. A 12-year-old girl with left brachiocephalic AVF, occlusion of bilateral venous brachiocephalic trunks, right internal jugular vein (after long use of CVLs) and collateral circulation.

In the patients from group 1 , during the 18 months of follow-up, 6 surgical interventions were performed: 2 interventions for creating a new AVF after the failure/ligation of the first, 2 cases of liga- tion of the fistula for aneurysm/pseudoaneurysm, an intervention to ligate a large collateral vessel (which was stealing blood from the arterialized vein), and a veno-venous bypass intervention with the insertion of a graft between the brachiocephalic venous trunks in a child with occlusion of the brachiocephalic venous trunk on the side of the fistula (for creation of a fistula flow circuit through the permeable contralateral venous brachiocephalic trunk; Figure 5).

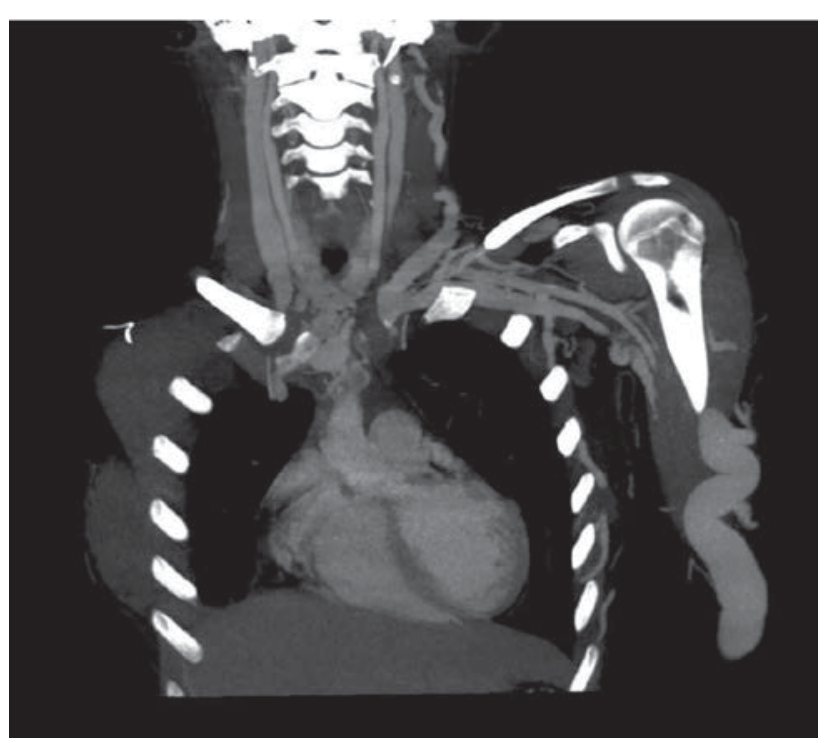

FIGURE 5a. Left venous brachiocephalic trunk occlusion with venous collateral circulation in a 14-year-old girl with left brachiocephalic fistula



FIGURE 5b. The same patient after performing a veno - venous by-pass through interposition of a prosthetic graft (thrombosed)

Of the patients with dialysis on CVLs, $16(76 \%)$ had at least one episode of sepsis that required hospitalization, and all patients who were dialyzed on a catheter (from the beginning or after fistula failure) experienced at least one episode of catheter 
vein thrombosis that required its change. In 8 patients (38\%) of the 21 patients using CVLs, thrombotic occlusion of at least one deep vein was observed at 3 months after the removal of the CVL from that venous axis.

\section{DISCUSSION}

Kidney transplantation is the first option for children with ESRD. Published data show that in children requiring hemodialysis, vascular access through CVLs is most commonly used. Although performing an AVF is not as easy as installing a CVL and an AVF takes time to mature before it can be used, the AVF should be considered the optimal method of vascular access in the absence of an imminent transplant. The main reason for performing AVF in these patients is the small size of the vessels, although there are studies that encourage performing AVF at a vein diameter of 1.5-2.5 mm [16]. In the group of patients presented in this paper, patients were accepted for AVF at a vein diameter of at least $3 \mathrm{~mm}$, and this probably contributed to the high rate of primary maturation $(86 \%)$, mostly similar with the results of a multi-center pediatric HD cohort study of Midwest Pediatric Nephrology Consortium in 2019 [17]. Primary patency was $72,7 \%$ at 18 months, higher than reported in a retrospective study of 47 patients published in Korea (2016) which reveal a primary patency of $60,5 \%$ at 1 year [7]. In contrast with this study, in our group the first choice in the majority of patients $(64 \%)$ was brachiocephalic fistula versus radiocephalic $(18 \%)$, in most cases the decision being supported by small diameters of radial artery and distal cephalic vein. In the Korean study radiocephalic fistula was performed in $82,7 \%$ of patients, and the minimum venous size diameter was only 2 millimeters. In this context, our data support the idea that a larger venous size diameter at the time of creation of AVF is related with a higher rate of primary patency. Aneurysms were present

\section{REFERENCES}

1. Shroff R, Calder F, Bakkaloğlu S, Nagler EV, Stuart S, Stronach L, Schmitt $\mathrm{CP}$, Heckert KH, Bourquelot $\mathrm{P}$, Wagner AM, Paglialonga F, Mitra S, Stefanidis CJ; European Society for Paediatric Nephrology Dialysis Working Group. Vascular access in children requiring maintenance haemodialysis: a consensus document by the European Society for Paediatric Nephrology Dialysis Working Group. Nephrol Dial Transplant. 2019 Oct 1;34(10):1746-1765.

2. Borzych-Duzalka D, Shroff R, Ariceta G, Yap YC, Paglialonga F, Xu H, Kang HG, Thumfart J, Aysun KB, Stefanidis CJ, Fila M, Sever L, Vondrak K, Szabo AJ, Szczepanska M, Ranchin B, Holtta T, Zaloszyc A, Bilge I, Warady BA, Schaefer F, Schmitt CP. Vascular Access in $27 \%$ of patients with $\mathrm{AVF}$, all of them having uncontrolled high blood pressure; there are no specific data regarding the incidence of aneurysm in pediatric population with AVF; in adult population, the incidence of aneurysms is reported to be high $(43,5 \%)$ in a narrative review of the published literature [18].

It is anticipated that the large-scale implementation of the current recommendations (2019) of the European Society of Pediatric Nephrology, which recommend a scheduled AVF approximately 3 months before use, will increase both the skills of vascular surgery specialists and the number of children who will benefit from this type of vascular access, to the detriment of central venous lines.

\section{CONCLUSIONS}

This study revealed several essential points for the prevention and treatment of AVF complications. Performing additional imaging (angio-CT for major deep veins in the area of interest) before performing an AVF in children who have had multiple central venous catheters may reveal occlusive/nonocclusive thrombosis in large venous trunks. These may contraindicate performing an AVF or indicate a different location for the AVF than was planned, or bypass surgery of the thrombosed segment. Effective control of hypertension can reduce the rate of formation and progression of AVF aneurysms. Use of a monitoring algorithm that includes periodic clinical follow-ups along with vascular ultrasound in these patients can ensure early detection of aneurysms/pseudoaneurysms, their progression rate, and the appearance of venous stenoses or thrombosis and enable timely treatment. Access to an interventional cardiology/ radiology service with skills in performing endovascular procedures on arteriovenous fistulas (dilation of vascular stenoses, implantation of stents/ stents-grafts to exclude aneurysms etc.) can be a major benefit in selected cases.

Conflict of interest: none declared Financial support: none declared

Choice, Complications, and Outcomes in Children on Maintenance Hemodialysis: Findings From the International Pediatric Hemodialysis Network (IPHN) Registry. Am J Kidney Dis. 2019 Aug;74(2):193-202.

3. Shroff R, Sterenborg RB, Kuchta A, Arnold A, Thomas N, Stronach L, Padayachee S, Calder F. A dedicated vascular access clinic for children on haemodialysis: Two years' experience. Pediatr Nephrol. 2016 Dec;31(12):2337-2344.

4. Ma A, Shroff R, Hothi D, Lopez MM, Veligratli F, Calder F, Rees L. A comparison of arteriovenous fistulas and central venous lines for long-term chronic haemodialysis. Pediatr Nephrol. 2013 Feb; 28(2):321-6 
5. Chand $\mathrm{DH}$, Valentini RP. International pediatric fistula first initiative: a call to action. Am J Kidney Dis. 2008 Jun;51(6):1016-24.

6. Gjorgjievski N, Dzekova-Vidimliski P, Gerasimovska V, Pavleska-Kuzmanovska S, Gjorgievska J, Dejanov P, Sikole A, Ivanovski N. Primary Failure of the Arteriovenous Fistula in Patients with Chronic Kidney Disease Stage 4/5. Open Access Maced J Med Sci. 2019 Jun 15;7(11):1782-1787.

7. Kim SM, Min SK, Ahn S, Min SI, Ha J. Outcomes of Arteriovenous Fistula for Hemodialysis in Pediatric and Adolescent Patients. Vasc Specialist Int. 2016 Sep;32(3):113-118.

8. Mudoni A, Cornacchiari M, Gallieni M, Guastoni C, McGrogan D, Logias F, Ferramosca E, Mereghetti M, Inston N. Aneurysms and pseudoaneurysms in dialysis access. Clin Kidney J. 2015 Aug; 8(4):363-7.

9. Pasklinsky G, Meisner RJ, Labropoulos N, Leon L, Gasparis AP, Landau D, Tassiopoulos AK, Pappas PJ. Management of true aneurysms of hemodialysis access fistulas. J Vasc Surg. 2011 May; 53(5):1291-7.

10. Rajput A, Rajan DK, Simons ME, Sniderman KW, Jaskolka JD, Beecroft JR, Kachura JR, Tan KT. Venous aneurysms in autogenous hemodialysis fistulas: is there an association with venous outflow stenosis. J Vasc Access. 2013 Apr-Jun;14(2):126-30.

11. Dixon BS. Why don't fistulas mature? Kidney Int. 2006 Oct; 70(8):1413-22.

12. Mennes PA, Gilula LA, Anderson CB, Etheredge EE, Weerts C Harter HR. Complications associated with arteriovenous fistulas in patients undergoing chronic hemodialysis. Arch Intern Med. 1978 Jul;138(7):1117-21.

13. Keeling AN, Naughton PA, McGrath FP, Conlon PJ, Lee MJ. Successful endovascular treatment of a hemodialysis graft pseudoaneurysm by covered stent and direct percutaneous thrombin injection. Semin Dial. 2008 Nov-Dec;21(6):553-6.

14. Mantha ML, Baer R, Bailey GS, Wu RL, Killen JP. Endovascular repair of a hemodialysis fistula aneurysm with covered stents. Kidney Int. 2009 Oct; 76(8):918.

15. Allaria PM, Costantini E, Lucatello A, Gandini E, Caligara F, Giangrande A. Aneurysm of arteriovenous fistula in uremic patients: is endograft a viable therapeutic approach? J Vasc Access. 2002 Apr-Jun;3(2):85-8.

16. Bourquelot P, Raynaud F, Pirozzi N. Microsurgery in children for creation of arteriovenous fistulas in renal and non-renal diseases. Ther Apher Dial. 2003 Dec;7(6):498-503.

17. Onder AM, Flynn JT, Billings AA, Deng F, DeFreitas M, Katsoufis C, Grinsell MM, Patterson LT, Jetton J, Fathallah-Shaykh S, Ranch D, Aviles D et al; Midwest Pediatric Nephrology Consortium. Predictors of patency for arteriovenous fistulae and grafts in pediatric hemodialysis patients. Pediatr Nephrol. 2019 Feb;34(2):329-339.

18. Mudoni A, Cornacchiari M, Gallieni M, Guastoni C, McGrogan D, Logias F, Ferramosca E, Mereghetti M, Inston N. Aneurysms and pseudoaneurysms in dialysis access. Clin Kidney J. 2015 Aug; 8(4):363-7. 